\title{
Motor Learning in Children with Neurofibromatosis Type I
}

\author{
Lianne C. Krab • Arja de Goede-Bolder • Femke K. Aarsen • Henriëtte A. Moll • \\ Chris I. De Zeeuw • Ype Elgersma • Josef N. van der Geest
}

Published online: 7 October 2010

(C) The Author(s) 2010. This article is published with open access at Springerlink.com

\begin{abstract}
The aim of this study was to quantify the frequently observed problems in motor control in Neurofibromatosis type 1 (NF1) using three tasks on motor performance and motor learning. A group of 70 children with NF1 was compared to age-matched controls. As expected, NF1 children showed substantial problems in visuo-motor integration (Beery VMI). Prism-induced hand movement adaptation seemed to be mildly affected. However, no significant impairments in the accuracy of simple eye or hand movements were observed. Also, saccadic eye movement adaptation, a cerebellum dependent task, appeared normal. These results suggest that the motor problems of children with NF1 in daily life are unlikely to originate solely from impairments in motor learning. Our findings, therefore, do not support a general dysfunction of the cerebellum in children with NF1.
\end{abstract}

\footnotetext{
L. C. Krab · A. de Goede-Bolder · H. A. Moll

Department of General Pediatrics,

Erasmus MC/Sophia Children's Hospital,

Rotterdam, The Netherlands

F. K. Aarsen

Department of Pediatric Neurology,

Erasmus MC/Sophia Children's Hospital,

Rotterdam, The Netherlands

L. C. Krab · C. I. De Zeeuw • Y. Elgersma •

J. N. van der Geest $(\square)$

Department of Neuroscience, Erasmus MC,

PO Box 2040, 3000-CA Rotterdam, The Netherlands

e-mail: j.vandergeest@erasmusmc.nl
}

C. I. De Zeeuw

Netherlands Institute for Neuroscience,

Amsterdam, The Netherlands
Keywords Neurofibromatosis type $1 \cdot$ Children $\cdot$ Motor deficits · Motor control · Eye movements · Hand movements

\section{Introduction}

Neurofibromatosis type 1 (NF1; incidence 1:3,000) is an autosomal dominant disease caused by a mutation in the gene for neurofibromin on chromosome $17 \mathrm{q} 11.2[1,2]$. NF1 is characterized by a variety of neurocutaneous symptoms and cognitive problems, the latter resulting in a lowered mean IQ and a variety of school problems [3]. In addition, many NF1 patients display impairments in fine and/or gross motor function, and over $40 \%$ of the NF1 children receive remedial teaching to alleviate or improve motor performance [3]. Fine motor problems are reported in areas of fine motor coordination, fine motor speed, and steadiness [4-6]. One of the neuropsychological tests consistently reported to be impaired in NF1 patients is the Beery Developmental test for visual-motor integration (Beery VMI [7]), a test for fine motor coordination and the integration between the visual-perceptual and motor abilities [3, 8-10]. Gross motor problems observed in NF1 include hypotonia and problems with motor coordination, balance, and gait $[4,9,11]$.

Although it is likely that the fine and gross motor problems in NF1 arise from deficits in a network of brain areas, the cerebellum could be of particular interest in NF1. The involvement of this particular brain structure in NF1 is suggested by behavioral, radiological, and molecular studies of NF1. Firstly, although NF1 patients are not clearly ataxic, the frequently reported clumsiness in movements [12, 13], could be related to deficits in the vermis, intermediate or lateral zones of the cerebellum [14]. Secondly, among other brain areas in the cerebrum and the brainstem $[4,5,9]$, the 
cerebellum is one of the preference sites for NF1 related hyperintensities visible on T2-weighted MR images, which have been related to impairment of fine motor skills [4]. Thirdly, NF1 specifically seems to affect GABA-ergic neurons [15-17], and the cerebellar GABA-ergic Purkinje neurons are among the highest neurofibromin expressing neurons in the brain $[18,19]$. In addition, it is suggested that the cerebellum may contribute to cognitive problems in childhood [20], although this notion has not been studied in children with NF1 directly.

The cerebellum plays an important role in motor performance, but also in motor learning, which refers to the ability to continuously adapt movements to optimize performance, a task which requires neuronal plasticity [21-27]. The motor learning capacities of children with NF1 have not been investigated so far. In the present study we quantitatively assessed motor performance and motor learning in a large group of children with NF1. A more detailed understanding of the motor problems in NF1 may contribute to the development of therapeutical and medicative interventions [28].

We assessed fine motor performance using the Beery VMI test, and cerebellar-mediated motor performance and motor learning using tests on eye movement and hand movement control, which are affected in patients with cerebellar deficits [26, 29-34]. Performance and plasticity of saccadic eye movements was examined in a saccade adaptation paradigm which assesses the gradual modification of the amplitude of saccadic eye movements induced by a systematic change in the visual environment [22]. Performance and plasticity of hand movement control was assessed using prism adaptation, which refers to the modification of hand movement trajectories in response to visual displacement of the environment induced by wearing prism goggles [35]. We hypothesized that motor learning capacities in children with NF1 are affected.

\section{Methods}

\section{Subjects}

Seventy children with NF1 (age, $12.3 \pm 2.5$ years; 36 boys, 34 girls; full scale IQ between 56 and 116 with a median of 87 ) and 19 healthy control children (age, $10.7 \pm 2.1$ years; six boys, 13 girls; full scale IQ between 76 and 131 with a median of 109) participated in this study. Twenty-two of 56 (40\%) children with NF1 received physiotherapy and 34 did not (14 cases missing). Children with NF1 were recruited from the patient group attending the NF1 outpatient clinic of the Erasmus MC-Sophia Children's Hospital in Rotterdam. Some of these children participated in this study in the context of a larger study of NF1 and cognition [3]. Inclusion criteria were NF1 diagnosis according to the criteria of the National Institutes of Health [36] and informed consent from the parents and from the children aged 12 years and older. Exclusion criteria were segmental NF1, pathology of the CNS (other than asymptomatic gliomas), deafness, severely impaired vision, use of anti-epileptics, inefficient production or comprehension of the Dutch language, and severe mental retardation (IQ below 48). The control subjects were children of employees of the Erasmus MC-Sophia Children's Hospital and were selected on the basis of age. The study was approved by the Medical Ethical Committee of the Erasmus MC.

\section{Procedure}

Subjects participated in three tasks the Beery VMI, a saccade adaptation test and a prism adaptation test.

\section{Beery VMI-Visual-Motor Integration}

Fine motor coordination and visual-motor integration was assessed with the Beery VMI task [7], in which children have to imitate or copy up to 30 geometric forms with increasing complexity using paper and pencil. The test was stopped when a child made more than two errors in a row. Copying errors were marked if they reflected problems in fine motor coordination, rather than a pure visuo-spatial problems. The task is specifically designed for children and takes about $10 \mathrm{~min}$. The test was administered and scored by a trained neuropsychologist. Beery VMI scores were standardized for age and gender using normative data for the general population [7]. Differences between the two groups were assessed using Kolmogorov-Smirnov tests.

\section{Saccade Adaptation-Eye Movement Control}

Performance and plasticity of saccadic eye movements was assessed in a classical backward saccade adaptation paradigm [34, 37]. Subjects were seated $70 \mathrm{~cm}$ in front of a 21-in. computer screen. This experiment took place in complete darkness. A red filter covered the computer screen to eliminate all light emitted by the monitor other than the visual stimuli. Binocular eye position was recorded using infrared video-oculography (EyeLink 2.04, SensoMotoric Instruments, Berlin, Germany) at a sample rate of $250 \mathrm{~Hz}$ $[34,38]$. Eye position was calibrated with the built-in ninepoint calibration routine. A chin rest ensured a stable position of the head and head movements were monitored using the built-in head-tracking camera.

The saccade adaptation paradigm consisted of three distinct phases: 20 baseline trials, followed by 100 adaptation trials, and 20 extinction trials. In all phases the subjects were instructed to look at a single red dot $\left(0.5^{\circ}\right.$ of visual angle in diameter) that jumped from left to right. 
Each trial started with the dot being displayed at $7.5^{\circ}$ of visual angle on the left side from the center of the screen. After fixation the dot was removed on the left and subsequently displayed $7.5^{\circ}$ from the center on the right side of the screen, evoking a primary saccadic eye movement from left to right with a target amplitude of $15^{\circ}$. In the baseline and the extinction trials the dot remained on the right side of the screen for $1.5 \mathrm{~s}$ after which the next trial was started. In the adaptation trials the dot on the right stepped $3^{\circ}$ to the left, i.e., $20 \%$ of the initial target amplitude backwards, during the saccadic eye movement toward it.

The amplitude of the primary saccade was determined for each of the 140 trials. Trials were discarded when the primary saccade did not start on the left side, was not directed toward the target on the right, or had an amplitude of less than $8^{\circ}$. For all trials, the saccadic Gain was defined as the amplitude of the primary saccade divided by the target amplitude $\left(15^{\circ}\right)$, so that a gain of 1 reflects a saccade that lands directly on target.

For each subject, the Baseline Gain was calculated as the average of the gains of the primary saccades made in the 20 baseline trials, and the Adapted Gain as the average of the gains of the last 20 trials in the adaptation phase. For each subject, the saccadic Gain Change was calculated as the difference between Adapted Gain and Baseline Gain. Saccadic Variability in the baseline and adapted phase was defined as the within-subject standard deviation of the primary saccadic gains in these phases.

If the Gain Change was larger than the mean Gain Change minus one standard deviation of the control group, and the difference between Baseline and Adapted Gains was significant $(p<0.01)$, an individual was said to have adapted his or her saccades.

\section{Prism Adaptation-Hand Movement Control}

The performance and plasticity of hand movement coordination was determined in a prism adaptation experiment [32]. Subjects were seated in front of a digitizing tablet (Ultrapad A2, WACOM Technologies Corporation, Vancouver, WA, USA). The target (a small cartoon picture) was projected from above on a see-through mirror, so that it seemed to be positioned on the tablet $20 \mathrm{~cm}$ straight ahead of the subject, while the hand was also visible. Visual feedback of hand position could be blocked by putting an opaque plate below the mirror, so that the target was still visible through the mirror but the hand below the mirror could no longer be seen (see Ref. [32] for details of the setup).

The experiment consisted of four phases. In all phases subjects had to move the pen a number of times from a starting position at the left bottom of the tablet $(17 \mathrm{~cm}$ from the center) towards the position of target over a movement distance of $26 \mathrm{~cm}$ with an angle of $50^{\circ}$. In the practice phase (phase 1) the subject had to move the pen towards the target ten times while they could see their hand (visual feedback). In the pre-adaptation phase (2) the subject had to move the pen ten times without visual feedback. In the adaptation phase (3) the subject wore prism glasses that shifted the visual world $10^{\circ}$ to the right. Subjects had to move the pen 30 times to the target and two additional practice-targets positioned about $17 \mathrm{~cm}$ to the left and right of the original target. In this phase they could see their hand again, so that the position of the hand and target could be visually aligned. Before the post-adaptation phase (4), the glasses were removed and subjects had to move the pen ten times without visual feedback.

The end-position of each hand movement across the tablet toward the target was marked manually. The movement angle (in degrees) and the movement distance (in centimeters) was calculated from the straight line between start- and end-position of the movement. For each subject, the averages and standard deviations of the movement angles and distances in the baseline phase, the pre-adaptation and the post-adaptation phase were determined. To assess the effect of wearing prism glasses (prism adaptation, also called the after-effect [24]), the change in average movement angle (Angle Change) between the pre- and post-adaptation phase was calculated.

If the Angle Change was larger than the mean Angle Change minus 1 standard deviation of the control group, and the difference between the average pre- and postadaptation angle was significant $(p<0.01)$, the subject was said to have adapted to the prism glasses.

Subjects had to hold the pen in their dominant right hand. Therefore, seven NF1 children and one control child who were left-handed were not eligible for this task.

To assess motor performance we compared the Beery VMI scores, baseline saccadic variability and variability in hand movement angle in the pre-adaptation phase between the two groups. To assess motor learning, we compared changes in saccadic gain and changes in movement angles between the two groups. Differences were statistically assessed by the nonparametric Mann-Whitney, Chi-square, and KolmogorovSmirnov tests. Spearman's correlations between Beery VMI scores and the motor performance and motor learning measures, and age and full scale IQ were calculated.

\section{Results}

\section{Beery VMI}

Beery VMI scores (Fig. 1a) were significantly lower in the NF1 group $(84 \pm 13, n=70)$ than in the control group $(102 \pm 14, n=19$, absolute extreme difference $=0.67, \mathrm{Z}=$ $2.58, p<0.001)$. Control children completed more items 


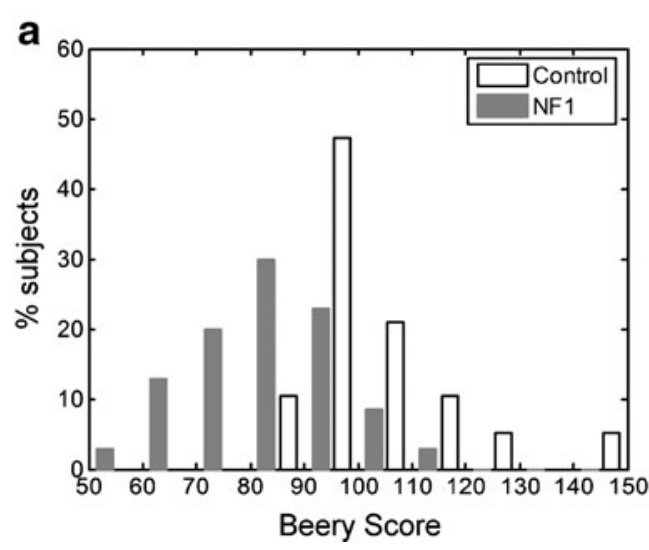

Fig. 1 Beery VMI: a shows the distribution of Beery VMI scores in 70 NF1 children and 19 age-matched controls; b shows examples of Beery VMI performance of two NF1 children and of two age-matched control children with around average Beery VMI score for their respective groups. Items illustrating pure motor problems in these two $\mathrm{NF}$ children were selected. Performance on item 2 is shown for a male NF1 child (age, 14.6 years; score, 79) and a male control (age,

than NF1 children (on average $22.3 \pm 2.0$ versus $19.6 \pm$ 3.9 , absolute extreme difference $0.371, \mathrm{Z}=1.44, p<0.05$ ) before the test was stopped. In the copying errors made in the NF1 group, but also in the control group, visual-spatial problems as well as problems in fine motor coordination were observed (see Fig. 1b). In the NF1 group, about $50 \%$ of the copying errors were related to problems in fine motor coordination, rather than to pure visuo-spatial problems, which was, however, not significantly different from controls. Children receiving physiotherapy did not differ from children not receiving physiotherapy (scores of $86 \pm 12$ vs $82 \pm 14$, respectively, $p=0.5$ ).

\section{Saccade Adaptation}

Seventy children with NF1 and 19 control children performed the saccade adaptation test. Seventeen NF1 children and seven controls were excluded from analysis b

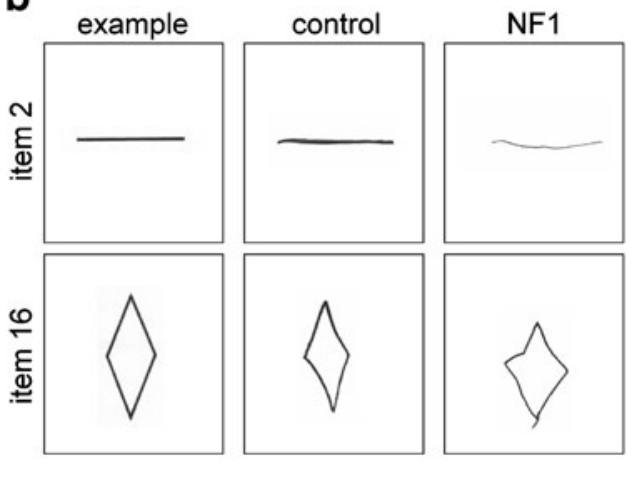

14.3 years; score, 97). The NF1 child drew an unsteady line, had a weak pencil stroke, and there was an indication of a very discrete tremor. Item 16 is shown for a male NF1 child (age, 10.9 years; score, 84 ) and a female control (age, 10.5 years; score, 103). The NF1 child shows a general delay in fine motor development and performs around developmental age 5.4 years on this item [7]. Note the slip of the pencil at the end of the movement

because of technical failures, including eye tracking difficulties, making too large head movements and making too few saccades for proper analysis.

We observed no differences in baseline saccadic performance between the remaining 53 children with NF1 (28 boys, 25 girls, $12.6 \pm 2.3$ years) and controls (two boys, nine girls, $10.8 \pm 2.1$ years). Specifically, the number of correct primary saccades in the 140 trials $(122 \pm 9$ for NF 1 vs. $124 \pm$ 9 for controls, $p=0.5)$, the baseline saccadic gains $(0.91 \pm$ 0.08 versus $0.93 \pm 0.04, p=0.4)$, and baseline saccadic variability $(0.10 \pm 0.04$ versus $0.08 \pm 0.02, p=0.2)$ did not differ between the two groups (Fig. 2a).

Saccadic adaptation was also not different in NF1 children compared to controls (Fig. 2b) with respect to the size of the adapted gains $(0.79 \pm 0.10$ for NF 1 vs. $0.78 \pm 0.10$ for controls, $p=0.9$ ) and the adapted saccade variability $(0.09 \pm 0.03$ versus $0.09 \pm 0.02, p=1.0)$. The saccadic gain change between baseline and the end of the adaptation
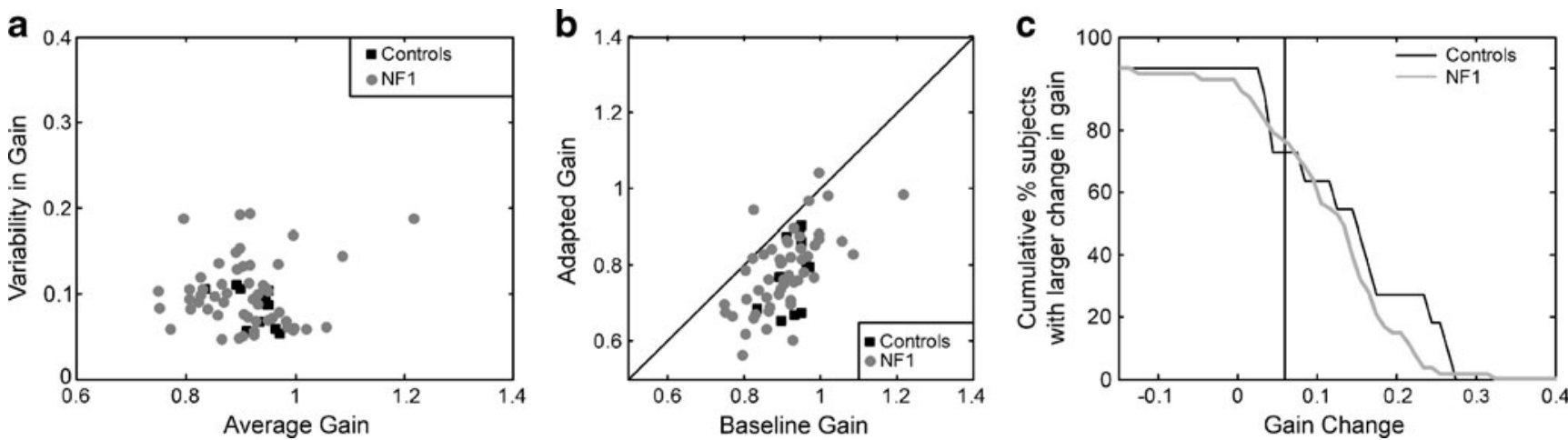

Fig. 2 Saccade adaptation: a shows the variability versus the average of the baseline saccadic gains of 53 NF1 children and 11 age-matched controls; each dot represents one individual subject. b Shows the adapted gain versus the baseline gain for these children; the oblique line is the unity line. c Shows the cumulative distribution of the Gain Changes in the NF1 and control groups. The vertical line (at Gain Change $=0.06$ ) indicates the cut-off for point significant saccade adaptation 
phase was also not significantly different between NF1 children and controls $(0.12 \pm 0.08$ versus $0.15 \pm 0.09, p=$ $0.3)$. The proportion of subjects with a significant gain change (Gain Change $>0.06$ as derived from the control group) was the same in the two groups (29 out of 53 NF1 children $(55 \%)$ versus 7 out of 11 controls $(64 \%), \chi^{2}=$ $0.294, p=0.6$ ). The distribution of individual Gain Changes was also not significantly different (absolute extreme difference $=0.235, \mathrm{Z}=0.709, p=0.7$, Fig. $2 \mathrm{c}$ ).

Age and full scale IQ were not related to the gain changes in children with NF1 or controls (age: $R=0.04, p=$ 0.8 for NF1 and $R=-0.13, p=0.7$ for controls; IQ: $R=0.07$, $p=0.6$ for NF1 and $R=0.62, p=0.1$ for controls).

\section{Prism Adaptation}

Sixty-three right-handed NF1 children and 18 right-handed control children were eligible for the prism adaptation task. Seven NF1 children were excluded from analysis because of technical problems including not understanding or adhering to task instructions. All remaining 56 children with NF1 (29 boys, 27 girls, $12.3 \pm 2.4$ years) and 18 controls (5 boys, 13 girls, $10.6 \pm 2.2$ years) were able to make accurate goal-directed hand movements towards the target. As expected, for both groups the movement angle was about $50^{\circ}$ and the movement distance was about $26 \mathrm{~cm}$ when children could align their hand visually with the target in the baseline phase. Without visual feedback (preadaptation phase) both groups became less accurate but no difference between the two groups was observed (movement angle: $56.8 \pm 3.2^{\circ}$ in NF1 vs. $55.6 \pm 2.8^{\circ}$ in controls, $p=0.2$; distance: $24.0 \pm 2.3 \mathrm{~cm}$ in NF1 vs. $24.0 \pm 2.0 \mathrm{~cm}$ in controls, $p=0.9$, see Fig. 3a). After wearing prism goggles with visual feedback in the adaptation phase, the average movements in the post-adaptation phase (also without feedback) did not differ between the groups (movement angle: $59.9 \pm 3.6^{\circ}$ in $\mathrm{NF} 1$ vs. $60.1 \pm 2.3^{\circ}$ in controls, $p=0.8$; distance: $24.0 \pm$ $2.3 \mathrm{~cm}$ in NF1 vs. $23.7 \pm 1.9 \mathrm{~cm}$ in controls, $p=0.7$ ). However, the changes in movement angle between the preadaptation and post-adaptation phase induced by the prism goggles was significantly smaller in NF1 children than in controls ( $3.1 \pm 3.0$ vs. $4.5 \pm 1.6^{\circ}$, respectively, $p=0.03$, see Fig. 3b).

As can be seen in Fig. 3b, some NF1 children did show a significant prism adaptation (Angle Change $>2.9^{\circ}$, as derived from the control group, with $p<0.01$ ). However, the proportion of subjects with a significant adaptation tended to be smaller in the NF1 group (28 out of $56 \mathrm{NF} 1$ children $(50 \%)$ ) than in the control group (13 out of 18 controls $\left.(72 \%), \chi^{2}=2.72, p=0.1\right)$. The difference in distributions of the changes in hand movement angles between the two groups was close to significance (absolute extreme difference $=0.375, Z=1.32, p=0.06$, see Fig. $3 c$ ).

Age and full scale IQ were not related to performance on prism adaptation in children with NF1 or controls (age: $R=$ $0.08, p=0.6$ for NF1 and $R=-0.32, p=0.2$ for controls; IQ: $R=0.20, p=0.1$ for NF1 and $R=0.44, p=0.1$ for controls). In addition, there were no differences in age or total IQ between the NF1 subgroups with or without significant adaptation $(p>0.1)$. Furthermore, the two subgroups of patients with or without significant prism adaptation did not differ from each other with respect to their scores on the Beery VMI test $(84 \pm 15$ vs. $86 \pm 10$, resp., $p=0.7)$, or the parameters obtained in the saccade adaptation test (all $p>$ $0.5)$. Finally, in both subgroups about half of the children received physiotherapy (eight of 22 children with significant adaptation and ten out of 21 without adaptation (13 missing), $p=0.5$ ).

In addition, we did not observe any correlations between performance on the Beery VMI test, the prism adaptation

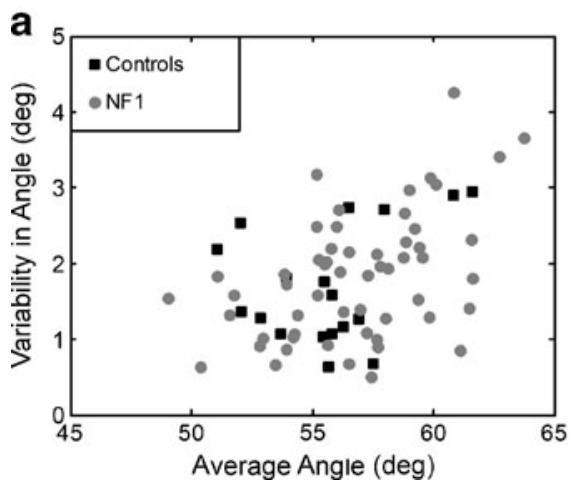

Fig. 3 Prism adaptation: a shows the variability versus the average hand movement angle of 56 NF 1 children and 18 healthy controls in the pre-adaptation condition (without visual feedback of the hand); each dot represents one individual subject. b shows the average angle of the arm movements in the post-adaptation phase versus the average angle of the
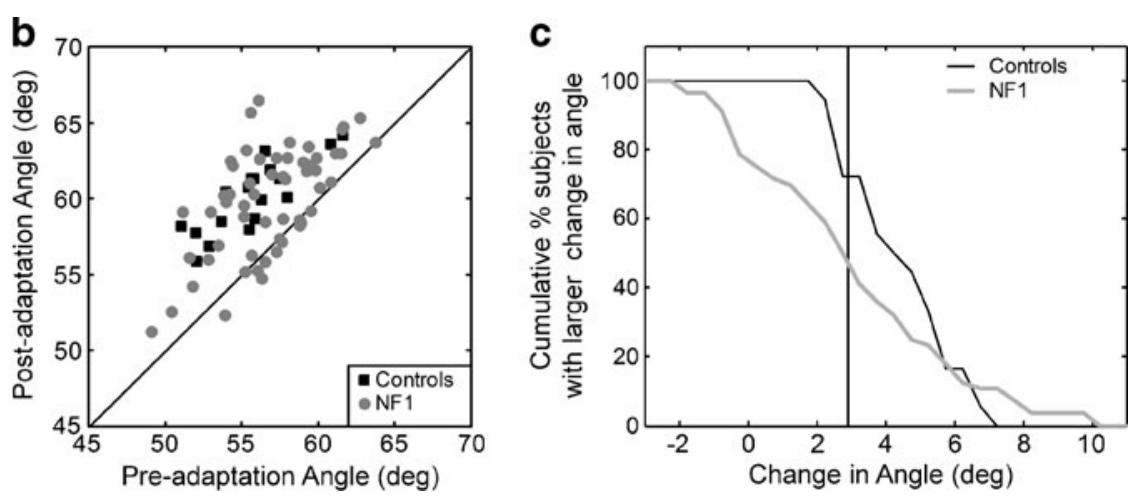

arm movements in the pre-adaptation phase for these children; the oblique line is the unity line. c Shows the cumulative distribution of the changes in average movement angles between the pre- and postadaptation phases in the NF1 and the control group. The vertical line indicates the cut-off point for significant prism adaptation $\left(2.9^{\circ}\right)$ 
test and the saccadic adaptation test in NF1 children and controls (all $p>0.5$ ).

\section{Discussion}

In the present study, motor performance and motor learning capacities of children with NF1 was assessed using the Beery VMI, saccade adaptation, and prism adaptation tasks. The performance of NF1 children was compared with healthy age-matched controls. As expected, children with NF1 show lower scores on the Beery VMI task than controls. In addition, the adaptation of hand movements to prism goggles was mildly impaired in NF1 children. However, saccadic performance and plasticity were not affected, as well as the performance of goal-directed hand movements. No effect of age and IQ was observed on the outcomes of the motor learning experiments.

As expected, NF1 children made more copying errors in the Beery VMI task than controls. We observed the typical visual-spatial problems, which are in line with the poorly developed visual-spatial skills of children with NF1 (reviewed by [39]). In addition, we found that half of the copying errors were related to problems of fine motor coordination. The presence of both types of problems indicates a general delay in fine motor skills compared to the normal population. Impairments in the Beery VMI can indicate problems in a variety of brain areas, including the right hemisphere, the primary motor cortex of the dominant hand, the cerebellum, subcortical nuclei, and/or the corpus callosum [7]. Furthermore, children receiving phsyiotherapy did not differ from children who did not, suggesting that getting physiotherapy is not directly linked to impairments in fine motor coordination. Our previous observation that the cognitive problems in NF1 are sometimes not treated adequately [3], might therefore also be applicable to the motor domain.

Baseline saccadic accuracy and the ability to adapt saccadic eye movements in NF1 appeared normal. In the present study, $55 \%$ of the NF1 and $64 \%$ of the control children were able to modify the amplitudes of their saccades in a classical saccade adaptation paradigm. These percentages are in good agreement with the $66 \%$ found in a group of 39 healthy children [40]. The saccadic oculomotor system comprises a network of brain areas, including the cerebellum and the parietal and frontal cortex, the basal ganglia, the superior colliculus and the brainstem [41]. The cerebellar oculomotor vermis is critically involved in maintaining a high saccadic accuracy [22-24]. Impairments in saccadic latencies and directions have been observed previously in a small group of ten children with NF1, which were postulated to reflect involvement of a broad (cortical) network of brain areas involved in saccadic control [42].
Our results suggest that the oculomotor vermis of the cerebellum is less likely to be part of that potentially deficient network in NF1.

Prism adaptation seems to be mildly impaired in children with NF1. Although both groups show a significant change in the angle of the hand movements after prism glass displacement, the average degree of adaptation is smaller in NF1 children. Furthermore, the variability in performance between NF1 children is larger than between control children and fewer NF1 children show a significant prisminduced after-effect. A subgroup of NF1 children could adapt their hand movements quite adequately, whereas others did not adapt at all. However, these two subgroups did not differ from each other on the Beery VMI test or the saccade adaptation task. This finding, therefore, seems to be in line with the large variability in clinical and cognitive characteristics between patients with NF1 [43]. Based on studies in cerebellar patients, impaired prism adaptation could result from problems in the anterior and caudal posterior lobe of the cerebellar cortex (including C1-C3 zones), but also upon other motor areas such as the ventral premotor cortex and the posterior parietal cortex, which is involved in visually directed movements [27, 44].

A potential limitation of our study is that a few NF1 children did not perform properly in the saccade and prism adaptation tasks, for instance by making large head movements, or by not making goal-directed hand movements, which excluded them from further analysis. This was likely due to a short attention span or inability to understand the instructions completely. Despite the efforts in optimizing the experimental procedures it is, however, inevitable that children, and especially pediatric patients, do not adhere as good as healthy adults to the instructions [40]. The rather demanding eye movement tests have been administered successfully in children with and without mental retardation $[32,34,40]$. We did not find any correlation between motor learning parameters and age or IQ in the present experiment. Although it could be argued that the attention and cognitive deficits in the excluded children is related to worse motor performance, the lack of correlation with age and IQ renders it less likely that their exclusion may have led to an overestimation of the performance of NF1 children on this task.

Taken together, our findings suggest that the motor problems displayed by children with NF1 are, at most, only partially related to deficits in plasticity of motor control. As reviewed above, mild abnormalities in hand movement adaptation may be caused by disturbances in specific areas in the cerebrum and cerebellum. However, the normal accuracy of eye and hand movements, as well as the adequate adaptation of saccadic eye movements in our study population, suggests that the alleged role of the cerebellum in NF1 may not be substantial. We conclude 
that it is unlikely that the motor problems in NF1 solely arise from a dysfunction of the cerebellum as a whole. The observed impairments in the prism adaptation task may be influenced by other brain areas.

The present manuscript deals with the performance on a variety of motor paradigms.. Although the performance on rather simple one-dimensional goal-directed movements in a laboratory setting do not seem to be affected in NF1, the fine motor skill of drawing figures in the Beery VMI is impaired. The latter task, which puts a high demand on the integration of cognitive and motor processes may be more representative of the control of more complex motor behavior needed for daily life activities, which is impaired in NF1, as can be readily seen in clinical practice [3]. Future research is necessary to unravel the neuronal basis of the behavioral problems in the NF1 patient population.

Acknowledgements We are very grateful to the patients and their parents for their participation. Also, we thank E. Barendse, S.M. Goorden, A.C. Gaemers, P. Plak, R. Wierenga, and M.J. Bouman for their help in collecting the data. We appreciate the support of all other participants of the NF1 clinical workgroup and the NF1 CoRe (Cognitive Research) team of the Erasmus MC-Sophia Children's Hospital Rotterdam, the Netherlands. This study was supported by the Hersenstichting Nederland, the Sophia Foundation for Medical Research, the Prinses Beatrix Fonds, and by a donation from the Dutch Neurofibromatosis Foundation.

Conflicts of interest The authors declare that there are no potential conflicts.

Open Access This article is distributed under the terms of the Creative Commons Attribution Noncommercial License which permits any noncommercial use, distribution, and reproduction in any medium, provided the original author(s) and source are credited.

\section{References}

1. Gutmann DH, Wood DL, Collins FS. Identification of the neurofibromatosis type 1 gene product. Proc Natl Acad Sci USA. 1991;88:9658-62.

2. Huson SM, Harper PS, Compston DA. Von Recklinghausen neurofibromatosis. A clinical and population study in south-east Wales. Brain. 1988;111(Pt 6):1355-81.

3. Krab LC, Aarsen FK, De Goede-Bolder A, Catsman-Berrevoets CE, Arts WF, Moll HA, et al. Impact of Neurofibromatosis type 1 on school performance. J Child Neurol. 2008;23:1002-10.

4. Feldmann R, Denecke J, Grenzebach M, Schuierer G, Weglage J. Neurofibromatosis type 1: motor and cognitive function and T2weighted MRI hyperintensities. Neurology. 2003;61:1725-8.

5. Moore BD, Slopis JM, Schomer D, Jackson EF, Levy BM. Neuropsychological significance of areas of high signal intensity on brain MRIs of children with neurofibromatosis. Neurology. 1996;46:1660-8.

6. Rowbotham I. Pit-ten Cate IM, Sonuga-Barke EJ, Huijbregts SC. Cognitive control in adolescents with neurofibromatosis type 1 . Neuropsychology. 2009;23:50-60.
7. Beery KE, Beery NA. The Beery-Buktenica developmental test of visual-motor integration. 5th ed. Minneapolis, NCS: Pearson Inc.; 2004.

8. Descheemaeker MJ, Ghesquiere P, Symons H, Fryns JP, Legius E. Behavioural, academic and neuropsychological profile of normally gifted Neurofibromatosis type 1 children. J Intellect Disabil Res. 2005;49:33-46.

9. North K, Joy P, Yuille D, Cocks N, Mobbs E, Hutchins P, et al. Specific learning disability in children with neurofibromatosis type 1: significance of MRI abnormalities. Neurology. 1994;44:878-83.

10. Dilts CV, Carey JC, Kircher JC, Hoffman RO, Creel D, Ward K, et al. Children and adolescents with neurofibromatosis 1: a behavioral phenotype. J Dev Behav Pediatr. 1996;17:229-39.

11. Chapman CA, Waber DP, Bassett N, Urion DK, Korf BR. Neurobehavioral profiles of children with neurofibromatosis 1 referred for learning disabilities are sex-specific. Am J Med Genet. 1996;67:127-32.

12. Cnossen MH, de Goede-Bolder A, van den Broek KM, Waasdorp $\mathrm{CM}$, Oranje AP, Stroink $\mathrm{H}$, et al. A prospective 10 year follow up study of patients with neurofibromatosis type 1. Arch Dis Child. 1998;78:408-12.

13. Korf BR. Clinical features and pathobiology of neurofibromatosis 1. J Child Neurol. 2002;17:573-7. discussion 602-4.

14. Gazzaniga MS, Ivry RB, Mangun GR. Cognitive Neurosciencethe biology of the mind. 1st ed. New York: W.W. Norton \& Company; 1998.

15. Costa RM, Federov NB, Kogan JH, Murphy GG, Stern J, Ohno $\mathrm{M}$, et al. Mechanism for the learning deficits in a mouse model of neurofibromatosis type 1. Nature. 2002;415:526-30.

16. Dasgupta B, Gutmann DH. Neurofibromatosis 1: closing the GAP between mice and men. Curr Opin Genet Dev. 2003;13:20-7.

17. Gutmann DH, Collins FS. The neurofibromatosis type 1 gene and its protein product, neurofibromin. Neuron. 1993;10:335-43.

18. Nordlund ML, Rizvi TA, Brannan CI, Ratner N. Neurofibromin expression and astrogliosis in neurofibromatosis (type 1) brains. J Neuropathol Exp Neurol. 1995;54:588-600.

19. Gutmann DH, Geist RT, Wright DE, Snider WD. Expression of the neurofibromatosis 1 (NF1) isoforms in developing and adult rat tissues. Cell Growth Differ. 1995;6:315-23.

20. Steinlin M. Cerebellar disorders in childhood: cognitive problems. Cerebellum. 2008;7:607-10.

21. Koekkoek SK, Hulscher HC, Dortland BR, Hensbroek RA, Elgersma Y, Ruigrok TJ, et al. Cerebellar LTD and learningdependent timing of conditioned eyelid responses. Science. 2003;301:1736-9.

22. Hopp JJ, Fuchs AF. The characteristics and neuronal substrate of saccadic eye movement plasticity. Prog Neurobiol. 2004;72:27-53.

23. Barash S, Melikyan A, Sivakov A, Zhang M, Glickstein M, Thier P. Saccadic dysmetria and adaptation after lesions of the cerebellar cortex. J Neurosci. 1999;19:10931-9.

24. Desmurget M, Pelisson D, Grethe JS, Alexander GE, Urquizar C, Prablanc C, et al. Functional adaptation of reactive saccades in humans: a PET study. Exp Brain Res. 2000;132:243-59.

25. Baizer JS, Kralj-Hans I, Glickstein M. Cerebellar lesions and prism adaptation in macaque monkeys. J Neurophysiol. 1999;81:1960-5.

26. Pisella L, Rossetti Y, Michel C, Rode G, Boisson D, Pelisson D, et al. Ipsidirectional impairment of prism adaptation after unilateral lesion of anterior cerebellum. Neurology. 2005;65:150-2.

27. Clower DM, Hoffman JM, Votaw JR, Faber TL, Woods RP, Alexander GE. Role of posterior parietal cortex in the recalibration of visually guided reaching. Nature. 1996;383:618-21.

28. Krab LC, de Goede-Bolder A, Aarsen FK, Pluijm SM, Bouman $\mathrm{MJ}$, van der Geest JN, et al. Effect of simvastatin on cognitive functioning in children with neurofibromatosis type 1: a randomized controlled trial. JAMA. 2008;300:287-94. 
29. Martin TA, Keating JG, Goodkin HP, Bastian AJ, Thach WT. Throwing while looking through prisms. I. Focal olivocerebellar lesions impair adaptation. Brain. 1996;119:1183-98.

30. Pisella L, Michel C, Grea H, Tilikete C, Vighetto A, Rossetti Y. Preserved prism adaptation in bilateral optic ataxia: strategic versus adaptive reaction to prisms. Exp Brain Res. 2004;156:399-408.

31. Fernandez-Ruiz J, Velasquez-Perez L, Diaz R, Drucker-Colin R, Perez-Gonzalez R, Canales N, et al. Prism adaptation in spinocerebellar ataxia type 2. Neuropsychologia. 2007;45:2692-8.

32. van der Geest JN, Lagers-van Haselen GC, van Hagen JM, Brenner E, Govaerts LC, et al. Visual depth processing in Williams-Beuren syndrome. Exp Brain Res. 2005;166:200-9.

33. Straube A, Deubel H, Ditterich J, Eggert T. Cerebellar lesions impair rapid saccade amplitude adaptation. Neurology. 2001;57:2105-8.

34. van der Geest JN, Lagers-van Haselen GC, Frens MA. Saccade adaptation in Williams-Beuren syndrome. IOVS. 2006;47:1464-8.

35. Redding GM, Rossetti Y, Wallace B. Applications of prism adaptation: a tutorial in theory and method. Neurosci Biobehav Rev. 2005;29:431-44.

36. NIH. National Institutes of Health Consensus Development Conference Statement: neurofibromatosis. Bethesda, Md., USA, July 13-15, 1987. Neurofibromatosis. 1988;1:172-8.
37. Frens MA, van Opstal AJ. Transfer of short-term adaptation in human saccadic eye movements. Exp Brain Res. 1994;100:293306.

38. van der Geest JN, Frens MA. Recording eye movements with video-oculography and scleral search coils: a direct comparison of two methods. J Neurosci Methods. 2002;114:185-95.

39. Ozonoff S. Cognitive impairment in neurofibromatosis type 1. Am J Med Genet. 1999;89:45-52.

40. Salman MS, Sharpe JA, Eizenman M, Lillakas L, To T, Westall C, et al. Saccadic adaptation in children. J Child Neurol. 2006;21:102531.

41. Robinson FR, Fuchs AF. The role of the cerebellum in voluntary eye movements. Annu Rev Neurosci. 2001;24:981-1004.

42. Lasker AG, Denckla MB, Zee DS. Ocular motor behavior of children with neurofibromatosis 1. J Child Neurol. 2003;18:348-55.

43. Easton DF, Ponder MA, Huson SM, Ponder BA. An analysis of variation in expression of neurofibromatosis (NF) type 1 (NF1): evidence for modifying genes. Am J Hum Genet. 1993;53:30513.

44. Kurata K, Hoshi E. Reacquisition deficits in prism adaptation after muscimol microinjection into the ventral premotor cortex of monkeys. J Neurophysiol. 1999;81:1927-38. 